\title{
Cytotoxic effect of a new 1,3,4-thiadiazolium mesoionic compound (MI-D) on cell lines of human melanoma
}

\author{
A Senff-Ribeiro', A Echevarria ${ }^{2}$, EF Silva ${ }^{2}$, CRC Franco ${ }^{3}$, SS Veiga ${ }^{3}$ and MBM Oliveira ${ }^{*, 1}$ \\ 'Department of Biochemistry and Molecular Biology, Federal University of Paraná, Curitiba, PR, Brazil; ${ }^{2}$ Department of Chemistry, Rural Federal University \\ of Rio de Janeiro, Rio de Janeiro, RJ, Brazil; ${ }^{3}$ Department of Cellular Biology, Federal University of Paraná, Curitiba, PR, Brazil
}

\begin{abstract}
The structural characteristics of mesoionic compounds, which contain distinct regions of positive and negative charges associated with a poly-heteroatomic system, enable them to cross cellular membranes and interact strongly with biomolecules. Potential biological applications have been described for mesoionic compounds. 1,3,4-Thiadiazolium mesoionic compound (MI-D), a new mesoionic compound, has been demonstrated to be extremely cytotoxic to BI6-FIO murine melanoma cells when compared to fotemustine and dacarbazine, drugs of reference in melanoma treatment protocols, describing inhibition of tumours grown in vitro and in vivo. We now evaluate the effects of mesoionic compound MI-D on different human melanoma cell lines. The drug decreased the viability and proliferation of MEL-85, SK-MEL, A2058 and MEWO cell lines in vitro, showing a considerable cytotoxic activity on these human cells. Adhesion of MEL-85 cells was evaluated in the presence of the drug using different extracellular matrix (ECM) constituents. MI-D decreased MEL-85 adhesion to laminin, fibronectin and matrigel. The morphology and actin cytoskeleton organisation of MEL-85 cells were also modified on MI-D treatment. These results on human melanoma cell lines indicate that MI-D is a very encouraging drug against melanoma, a tumour that is extremely resistant to chemotherapy. British Journal of Cancer (2004) 9 I, 297-304. doi: I0.1038/sj.bjc.6601946 www.bjcancer.com
\end{abstract}

Published online 15 June 2004

(c) 2004 Cancer Research UK

Keywords: mesoionic compounds; MI-D; antimelanoma activity; human melanoma cell lines

Compounds of the mesoionic class have interesting structural features provided by their betaine-like character. They consist of a five-membered heterocyclic ring associated with a sextet of $\mathrm{p}$ and $\pi$ electrons, supporting a partial positive charge in the heterocyclic ring, which is counterbalanced by a formal negative charge on the atom of the $\alpha$-side chain (Ollis and Ramsden, 1976; Newton and Ramsden, 1982; Cheung et al, 1992). The association of these characteristics suggests a high probability of strong interactions with biomolecules such as DNA and/or proteins. Although mesoionic compounds are internally charged, they are neutral overall, and can therefore cross biological membranes in vivo (Kier and Roche, 1967).

All the different classes of mesoionic compounds (sydnones, sydnonimines, isosydnones and 1,3,4-thiadiazoles) have received considerable attention and have been extensively studied because of their unique structures, reaction behaviour, biological activities and possible pharmaceutical use (Moustafa and Eisa, 1991; Corell et al, 1994; Rehse et al, 1995; Satyanarayana and Rao, 1995). These include anti-inflammatory, analgesic, antibacterial, antifungal and antitumour activities (Badachikar et al, 1986; Shinzato et al, 1989; Moustafa and Eisa, 1991; Grynberg et al, 1992; Montanari et al, 1992; Satyanarayana and Rao, 1995; Grynberg et al, 1997; Senff-

*Correspondence: Dr MBM Oliveira, Department of Biochemistry and Molecular Biology, Federal University of Paraná, Centro Politécnico, Jardim das Américas, Curitiba, Paraná, CEP 81.531-990, CP 19046, Brazil; E-mail: mbmo@ufpr.br

Revised 27 April 2004; accepted 28 April 2004; published online 15 June 2004
Ribeiro et al, 2003, 2004). Potent antiplatelet, fibrinolytic, thrombolytic and broncholytic effects (Corell et al, 1994; Kankaanranta et al, 1996), and effects on the cardiovascular system (Majid et al, 1980; Rudolph and Derschinger, 1991; Rehse and Konig, 1995; Rehse et al, 1995) have also been described for mesoionic compounds. Some effects described for these compounds are intimately related to the presence of specific substituent groups on the ring (Corell et al, 1994; Satyanarayana and Rao, 1995; Kankaanranta et al, 1996; Grynberg et al, 1997), or to the ability to release nitric oxide from their molecular structures (Hogg et al, 1992).

A new mesoionic compound, 4-phenyl-5-(4-nitrocinnamoyl)1,3,4-thiadiazolium-2-phenylamine chloride (MI-D) was synthesised by Grynberg et al (1997) (Figure 1), for which it was shown the enhancement of the survival of Ehrlich carcinoma and Sarcoma-180 tumour-bearing mice, preventing tumour growth, with no significant concomitant alterations in the haematological parameters of tested animals, at a dose of $25 \mathrm{mg} \mathrm{kg}^{-1}$ $\left(57 \mu \mathrm{mol} \mathrm{kg}^{-1}\right)$.

MI-D was shown to be able to inhibit the respiratory chain between complexes II and III, collapse the transmembrane potential, and stimulate ATPase activity in intact mitochondria (Cadena et al, 1998). Alterations were also reported in membrane permeability and fluidity, which are related to its effect on the energy-linked functions of mitochondria (Cadena et al, 2002).

Recent studies in our laboratory evaluating a series of 1,3,4thiadiazolium mesoionics showed that MI-D, which has an $\mathrm{NO}_{2}$ substituent on the cinnamoyl ring, was the most effective against the melanoma murine model B16-F10 (Senff-Ribeiro et al, 2004). Compared with two other antineoplastic agents (fotemustine and 


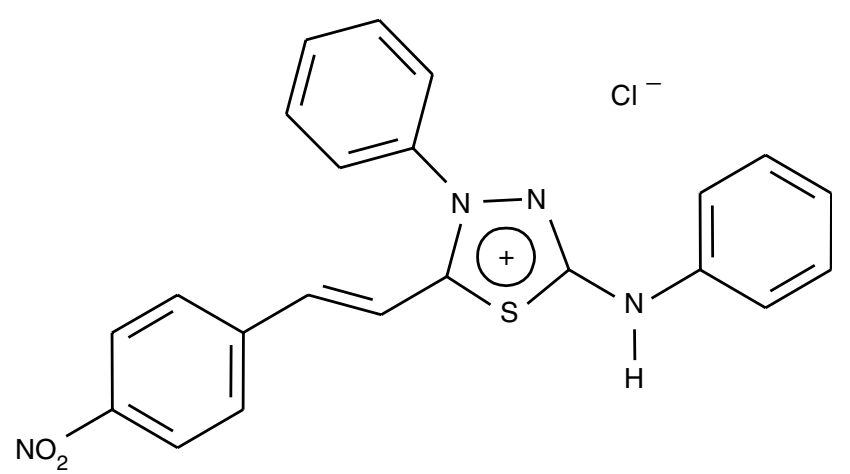

Figure I Chemical structure of 4-phenyl-5-(4-nitrocinnamoyl)-I,3,4thiadiazolium-2-phenylamine chloride (MI-D).

dacarbazine), it was effective against the murine model both in vitro and in vivo, under the same experimental conditions and with the same molar concentrations (Senff-Ribeiro et al, 2003).

Although antitumour effects against Ehrlich and Sarcoma-180 tumour models, and even against the aggressive melanoma murine model B16-F10, have already been demonstrated for MI-D (Grynberg et al, 1997; Senff-Ribeiro et al, 2003, 2004), it has not been tested against human melanoma cell lines.

We now study the effects of MI-D on four established human melanoma cell lines: MEL-85, SK-MEL, A2058 and MEWO. The in vitro viabilities and proliferations of these cell lines in the presence of MI-D were evaluated. In order to obtain further insights concerning MI-D's anti-melanoma activity, cell features of adhesion, morphology and actin cytoskeleton organisation, which are deeply related to the development and establishment of tumours, were also subjects studied using the MEL-85 cell line.

\section{MATERIALS AND METHODS}

\section{Materials}

MI-D (4-phenyl-5-(4-nitro-cinnamoyl)-1,3,4-thiadiazolium-2-phenylamine chloride) was synthesised in the Department of Chemistry of the Rural Federal University of Rio de Janeiro, Brazil, as described elsewhere (Grynberg et al, 1997). Its structure was confirmed by ${ }^{1} \mathrm{H}$ - and ${ }^{13} \mathrm{C}-\mathrm{NMR}$ spectroscopy and mass spectrometry. Dulbecco's modified Eagle's medium (DMEM), RPMI1640 medium and fetal bovine serum (FBS) were obtained from Cultilab (Campinas, Brazil); penicillin and gentamycin were both purchased from GIBCO (Bethesda, USA). Paraformaldehyde (20\%, aqueous solution) was from EMS (Electron Microscopy Sciences, Washington, USA). Phalloidin labelled with FITC was from Molecular Probes (Eugene, USA) and the aqueous mounting medium, Fluormount- $\mathrm{G}^{\mathbb{R}}$ from EMS (Washington, USA). Trypan blue, MTT, crystal violet and glycine were obtained from Sigma Aldrich (St Louis, USA). DMSO was from Merck. All other reagents were commercial products of the highest available purity grade.

\section{Drug solutions}

MI-D was dissolved in dimethylsulphoxide (DMSO) for its experimental use. In order to minimise solvent interference, several stock solutions of MI-D were prepared so that at the desired final concentrations of MI-D in the assays, the amounts of DMSO were identical and equal to $0.12 \%$.

\section{Cell lines and culture conditions}

Human melanoma cell lines used in this study were kindly provided by the Ludwig Institute for Cancer Research (São Paulo,
Brazil). Cells were maintained in liquid nitrogen with a low number of passages. After thawing, the cells were grown in monolayer cultures in the appropriate media containing penicillin $\left(100 \mathrm{U} \mathrm{ml}^{-1}\right)$ and gentamicin $\left(50 \mu \mathrm{g} \mathrm{ml}^{-1}\right)$. MEL-85 and MEWO cells were cultured in RPMI containing 10\% FBS, SK-MEL cells in RPMI containing 15\% FBS and A2058 cells in DMEM containing $10 \%$ FBS. The cultures were kept at $37^{\circ} \mathrm{C}$ under a humidified atmosphere plus $5 \% \mathrm{CO}_{2}$. Release of cells was performed by a treatment for a few minutes with a $2 \mathrm{~mm}$ solution of ethylenediaminetetraacetic acid (EDTA) in phosphate-buffered saline (PBS). After being counted, cells were then resuspended in an adequate volume of the respective medium supplemented with FBS and again plated in the presence or absence of MI-D.

\section{Cell viability assay}

Viability assays were carried out on 24-well plates (TPP, Trasadingen, Switzerland). Human melanoma cells $\left(5 \times 10^{5}\right.$ cells well $\left.^{-1}\right)$ were plated and allowed to adhere and grown for $20 \mathrm{~h}$ before incubation with the drug. MI-D was added in varying concentrations up to $75 \mu \mathrm{M}$. At each determined interval (24 and $48 \mathrm{~h}$ ), supernatants and cells were harvested, centrifuged, washed with PBS and the viability was measured by the Trypan blue-exclusion assay (Phillips, 1973). Briefly, Trypan blue $(0.4 \%$ in PBS, pH 7.4) was added to the cell suspension and the number of viable (unstained) and nonviable (stained) cells was counted using a Neubauer Chamber. For control experiments, the appropriate medium contained adequate amounts of vehicle ( $0.12 \%$ of DMSO). Cell viability of controls was normalised to $100 \%$.

\section{Cell proliferation assay}

Human melanoma cells $\left(6 \times 10^{3}\right.$ cells well $\left.^{-1}\right)$ were grown for $16 \mathrm{~h}$ on 96-well plates (TPP) containing an appropriate medium supplemented with an adequate amount of FBS. The medium was then replaced by a serum-free one. After $24 \mathrm{~h}$, this was replaced with the respective medium containing the usual concentrations of FBS plus $\mathrm{MI}-\mathrm{D}$, at different concentrations $(2.5-25 \mu \mathrm{M})$ in quadruplicate. Controls consisted of the respective medium alone or in the presence of $0.12 \%$ DMSO, which was the MI-D solvent. After 24,48 and $72 \mathrm{~h}$ the number of cells in each well was determined using the MTT method (Mosmann, 1983). MTT [3-(4,5-dimethylthiazol-2-yl)2,5-diphenyl tetrazolium bromide] was dissolved in Hanks' balanced saline solution (HBSS) at $5 \mathrm{mg} \mathrm{ml}^{-1}$. At the above intervals, $20 \mu \mathrm{l}$ of the MTT solution were added to each well and the plates were incubated at $37^{\circ} \mathrm{C}$ for $3 \mathrm{~h}$. The MTT solution was removed and DMSO was added and mixed thoroughly to dissolve the dark-blue crystals. The plates were then read using a Microelisa Reader (Bio-Rad, Madison, USA) at $550 \mathrm{~nm}$ for sample and $655 \mathrm{~nm}$ for reference. Results are expressed as the cell number, which was determined using a standard curve of cells against absorbance.

\section{Cell adhesion assay}

Native fibronectin was purified from fresh human plasma according to the procedure of Engvall and Ruoslahti (1977). Laminin and matrigel, a reconstituted basement membrane, were purified from a Engelbreth-Holm-Swarm (EHS) tumour as described by Paulsson et al (1987) and Kleinman et al (1986), respectively. The presence and purity of proteins were assessed by both an electrophoretic analysis on sodium dodecyl sulphatepolyacrylamide gel electrophoresis (SDS-PAGE) and Western blot. Adhesion assays were performed as described by Saiki et al (1989) with some modifications. Briefly, MEL-85 cells $\left(4 \times 10^{4}\right)$ with or without MI-D $(0.5,1.0,2.5$ and $5.0 \mu \mathrm{M})$ were added to microculture wells (96-well plates, TPP) precoated with fibronectin, laminin or matrigel $\left(10 \mu \mathrm{g} \mathrm{ml}^{-1}\right)$ and blocked with bovine serum albumin (BSA) $1 \%$. The cultures were incubated at $37^{\circ} \mathrm{C}$ for 
$2 \mathrm{~h}$. The wells were washed twice with warm PBS to remove unattached cells, and then the attached cells were fixed with methanol and stained with $0.8 \%$ crystal violet dissolved in $20 \%$ ethanol. After extensive washing with PBS, the dye was eluted with $50 \%$ ethanol in $0.05 \mathrm{M}$ sodium citrate and the absorbance was measured at $550 \mathrm{~nm}$ using a MicroElisa Reader (BioRad). At the end of the experiment, the plates were photographed (LeicaMPS30) using an inverted microscope (Leica-DMIL). The control contained the same amount of DMSO as the tested wells $(0.12 \%$ of DMSO) and its cellular adhesion was normalised to $100 \%$.

\section{Cell morphology analysis}

MEL-85 cells were cultured on glass coverslides for $16 \mathrm{~h}$ at $37^{\circ} \mathrm{C}$ under a humidified atmosphere plus $5 \% \mathrm{CO}_{2}$. Cells were treated with 25 and $50 \mu \mathrm{M}$ MI-D for $2 \mathrm{~h}$. After treatment, they were washed twice with PBS and fixed with $2 \%$ paraformaldehyde in PBS for $30 \mathrm{~min}$ at $4{ }^{\circ} \mathrm{C}$. For the control, the appropriate medium contained adequate amounts of vehicle ( $0.12 \%$ of DMSO). Coverslides were stained by Giemsa and studied by bright-field microscopy (Olympus BX40). Images were acquired $(\times 400)$ in grayscale using a software Image-Plus 4.0 version (Media Cybernetics, Silver Spring, USA). A morphometric analysis was performed using an ImageTool software 3.00 version (University of Texas Health Science Center in San Antonio, USA). Cell features, such as area, elongation and roundness of about 400 cells were analysed. For analysis, the area of the object, measured as the number of pixels in the polygon was converted to percent. Elongation was measured as the ratio of the length of the major axis to the length of the minor axis. The result was a value of between 0 and 1 that was converted to $\%$ for analysis to obtain an analytical value. Roundness was computed as: $\left(4 \pi \times\right.$ area)/perimeter ${ }^{2}$. The result gave a value of between 0 and 1 that was converted to \% for analysis.

\section{Immunofluorescence microscopy}

MEL-85 cells $\left(5 \times 10^{4}\right)$ were plated on glass coverslides $(13 \mathrm{~mm}$ diameter), which were prepared for confocal immunofluorescence microscopy. After $16 \mathrm{~h}$, MEL-85 cells were incubated with $50 \mu \mathrm{M}$ MI-D for $2 \mathrm{~h}$ at $37^{\circ} \mathrm{C}$ under a humidified atmosphere plus $5 \% \mathrm{CO}_{2}$. In the control, the appropriate medium contained adequate amounts of vehicle $(0.12 \%$ of DMSO). Cells were washed twice with PBS and fixed with $2 \%$ paraformaldehyde in PBS for $30 \mathrm{~min}$ at $4^{\circ} \mathrm{C}$. Cells on coverslides were incubated with $0.1 \mathrm{M}$ glycine for 3 min, washed with PBS and then blocked with PBS containing $1 \%$ BSA for $30 \mathrm{~min}$ at room temperature $\left(25^{\circ} \mathrm{C}\right)$. After washing thrice with PBS, coverslides were incubated with phalloidine conjugated with fluorescein isothiocyanate (FITC) (Molecular Probes) diluted in PBS $(1: 200)$ for $20 \mathrm{~min}$. After washing with PBS $(10 \times)$ and once in water, slides were mounted with Fluormont- ${ }^{\circledR}$. Cells were observed using a confocal fluorescence microscope (Confocal Radiance 2100, Bio-Rad) coupled to a Nikon Eclipse 800 with plan apochromatic objectives (Science and Technologies Group Instruments Division, Melville, USA). Images were acquired $(\times 600)$ using Radiance 2100 (Bio-Rad).

\section{Statistical analysis}

Statistical analysis of data were carried out using analysis of variance (ANOVA) and the Tukey test for average comparison. Mean \pm s.d. values were used. Significance was defined as $P<0.05$.

\section{RESULTS}

\section{Effect of MI-D on cell viability}

Figure 2 shows the effect of the mesoionic compound on the viability of human melanoma cell lines evaluated 24 and $48 \mathrm{~h}$ after treatment with different concentrations of MI-D $(2.5-75 \mu \mathrm{M})$. Time- and dose-dependent effects were shown by MI-D on the four cell lines studied.

The viability of MEL- 85 cells was reduced to $56 \%$ after a $24 \mathrm{~h}$ treatment with $10 \mu \mathrm{M}$ MI-D (Figure 2A). At this time of incubation, $75 \mu \mathrm{M}$ MI-D diminished the viability by $\sim 82 \%$. When a treatment of $48 \mathrm{~h}$ was used, the maximum cytotoxic effect (100\%) was
A

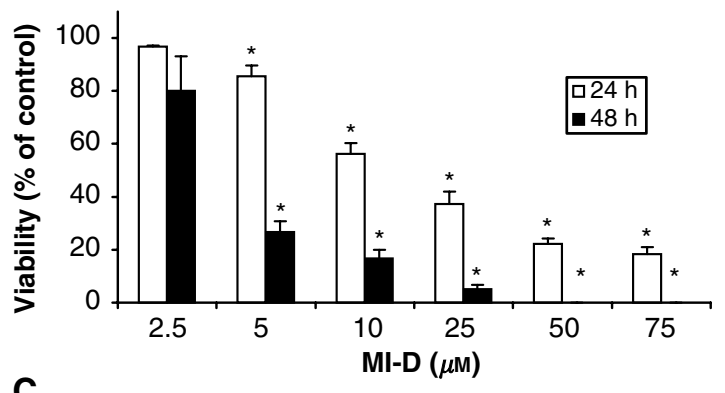

C

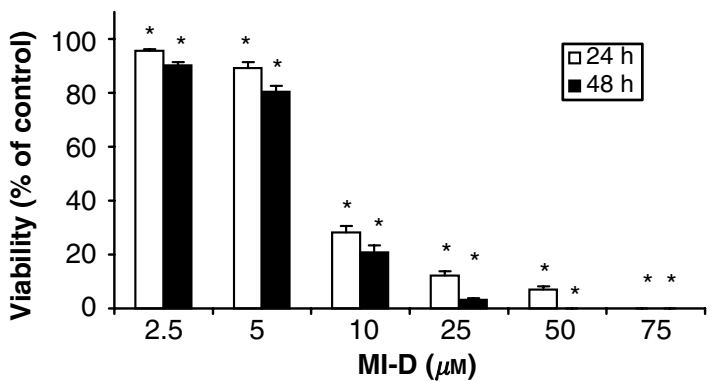

B

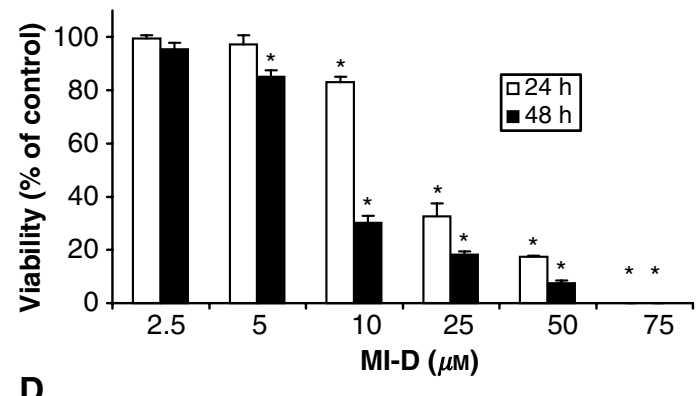

D

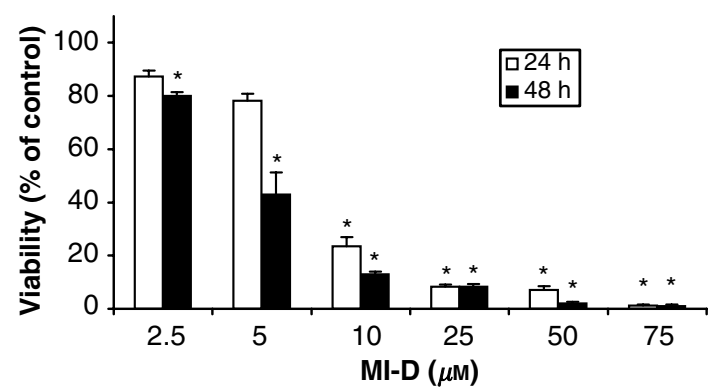

Figure 2 Effects of MI-D on the viability of different human melanoma cell lines. (A) Effects of MI-D on MEL-85 cells. (B) Effects of MI-D on SK-MEL cells. (C) Effects of MI-D on A2058 cells. (D) Effects of MI-D on MEWO cells. The viability of melanoma cells was measured at indicated intervals and concentrations of MI-D using the trypan blue-exclusion assay $(n=4)$. Values given are the mean \pm s.d. $* P<0.00$ l. 
reached starting from $50 \mu \mathrm{M}$. A measure of $5 \mu \mathrm{M}$ MI-D reduced the number of viable cells to $27 \%$ after $48 \mathrm{~h}$ incubation.

SK-MEL cells also had their viability diminished by MI-D treatment (Figure 2B). After $24 \mathrm{~h}, 25 \mu \mathrm{M}$ MI-D reduced the viability to $\sim 30 \%$ and at $50 \mu \mathrm{M}$ to $17 \%$. When the concentration was raised to $75 \mu \mathrm{M}$, there were no viable cells after $24 \mathrm{~h}$ incubation. A volume of $10 \mu \mathrm{M}$ MI-D reduced the viability to $30 \%$ after $48 \mathrm{~h}$. At this time, there was more than $90 \%$ of cell death using $50 \mu \mathrm{M}$ MI-D.

The viability of A2058 cells was decreased to $\sim 30 \%$ when the concentration of MI-D was $10 \mu \mathrm{M}$ and the incubation time was $24 \mathrm{~h}$ (Figure 2C). At this time, the concentrations of 25 and $50 \mu \mathrm{M}$ reduced the number of viable cells to 12 and $7 \%$, respectively. When a $48 \mathrm{~h}$ incubation was assayed, $10 \mu \mathrm{M}$ MI-D reduced the viability to $20 \%$ and $25 \mu \mathrm{m}$ almost gave a maximum cytotoxic effect (97\%). At this time, all A2058 cells were dead when the concentration of MI-D was $50 \mu \mathrm{M}$.

MEWO cells were also very sensitive to the toxic effects of MI-D (Figure 2D). After $24 \mathrm{~h}, \mathrm{MI}-\mathrm{D}$ at 10 and $25 \mu \mathrm{M}$ concentrations, diminished the viability to 23 and $8 \%$, respectively. Increasing the drug concentration to $75 \mu \mathrm{M}$ resulted in only $\sim 1 \%$ of viable cells after $24 \mathrm{~h}$. When a $48 \mathrm{~h}$ treatment was performed, $10 \mu \mathrm{M}$ MI-D reduced the number of viable cells to $13 \%$ while $50 \mu \mathrm{m}$ gave rise to $\sim 100 \%$ cell death.

\section{Effect of MI-D on cell growth}

Evaluation of the effect of MI-D on the growth of human melanoma cell lines was performed using a growth-time kinetic study of up to $72 \mathrm{~h}$ (Figure 3). Proliferation of all melanoma cell lines was greatly inhibited by MI-D, even when subcytotoxic concentrations $(1-2.5 \mu \mathrm{M})$ were tested.

MEL-85 cells (Figure 3A) treated with $5 \mu \mathrm{M}$ MI-D gave a $50 \%$ reduction of cell growth during the $72 \mathrm{~h}$ experiment. At a concentration of $10 \mu \mathrm{M}$, the proliferation of MEL-85 cells was completely inhibited.

No growth of SK-MEL cells (Figure 3B) was observed when $5 \mu \mathrm{M}$ MI-D was used. After $24 \mathrm{~h}, 1$ and $2.5 \mu \mathrm{M}$ MI-D reduced the number of cells to $\sim 65$ and $\sim 55 \%$, respectively.

A2058 cells (Figure 3C) had their growth reduced to $55-61 \%$ when the concentration was $2.5 \mu \mathrm{M}$. When MI-D was used at $5 \mu \mathrm{M}$, there was no increase in cell number up to $48 \mathrm{~h}$. However, at $72 \mathrm{~h}$ there was a recovery and the number of cells increased, being $46 \%$ of the control.

The proliferation of MEWO cells was inhibited by MI-D (Figure 3D). At a low MI-D dose $(2.5 \mu \mathrm{M})$ a decrease of cell number of a quarter after 48 and $72 \mathrm{~h}$ was observed. The concentration of $5 \mu \mathrm{m}$ allowed cell growth up to $24 \mathrm{~h}$, but after there was no increase in cell number up to $72 \mathrm{~h}$. In all, $10 \mu \mathrm{M}$ MI-D did not allow MEWO growth. It must be pointed out that all cell lines, when exposed to MI-D at $10 \mu \mathrm{M}$ or more, did not grow and extensive cell death was observed, confirming the previous data appearing in Figure 2.

\section{Effect of MI-D on MEL-85 adhesion to laminin, fibronectin and matrigel}

Figure 4 shows the effects of MI-D on MEL-85 adhesion to extracellular matrix (ECM) constituents, such as laminin, fibronectin and matrigel. Although there were apparent decreases on cell adhesion when 0.5 and $1 \mu \mathrm{M}$ of MI-D were used, the values were not statistically different from those of the controls. Higher concentrations of MI-D significantly inhibited MEL-85 adhesion to ECM molecules in a concentration-dependent manner. Adhesion to laminin and fibronectin was decreased to 70 and $55 \%$ by 2.5 and $5 \mu \mathrm{M}$ of MI-D, respectively, after $2 \mathrm{~h}$ exposure (Figures $4 \mathrm{~A}$ and $\mathrm{B}$ ). At $5 \mu \mathrm{M}$, MI-D diminished MEL-85 adhesion to laminin to $\sim 65 \%$
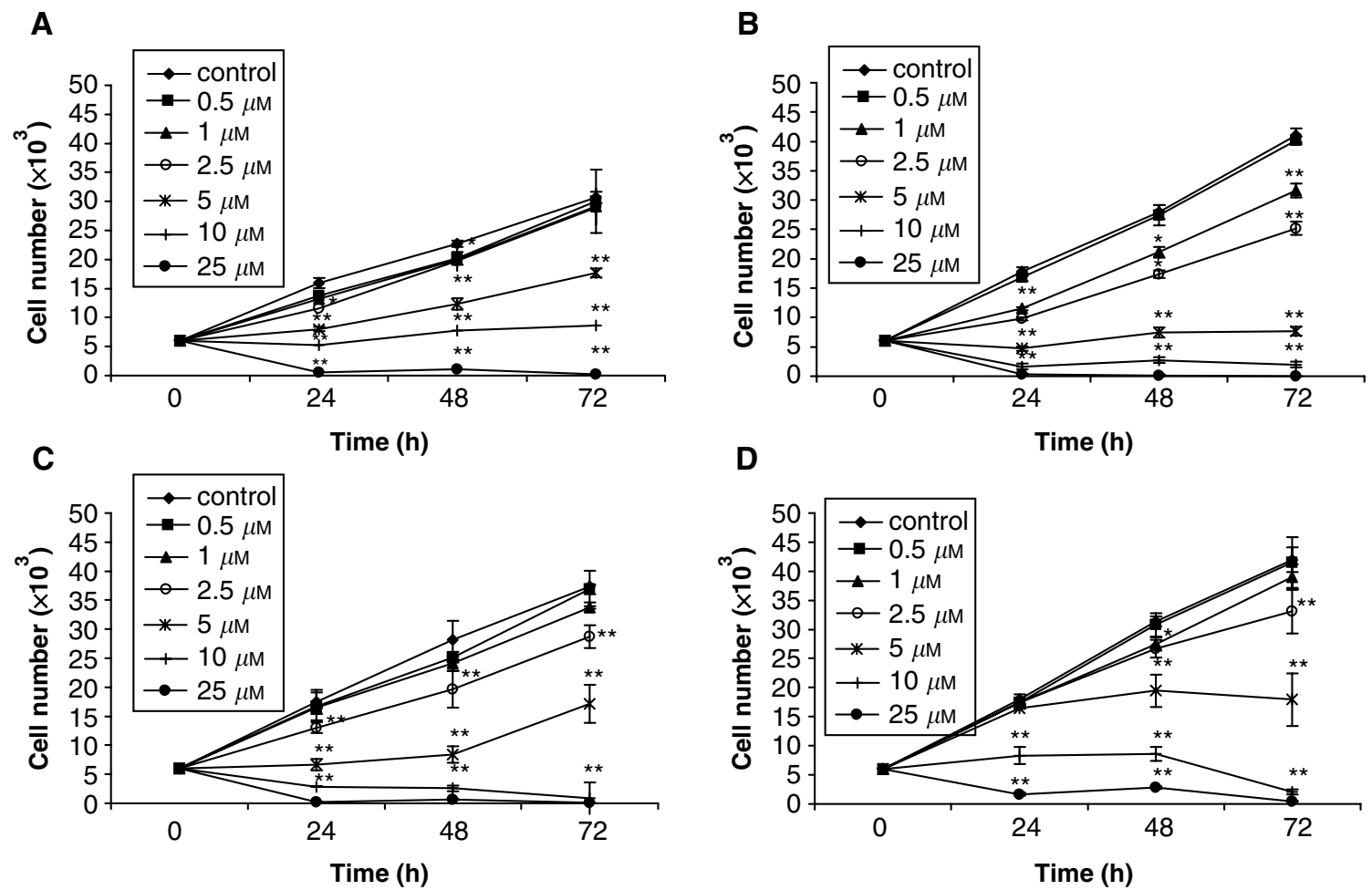

Figure 3 Effects of MI-D on the proliferation of human melanoma cell lines. (A) Effects of MI-D on MEL-85 cells. (B) Effects of MI-D on SK-MEL cells. (C) Effects of MI-D on A2058 cells. (D) Effects of MI-D on MEWO cells. The proliferation rates were measured using the MTT method at the times indicated and at subcytotoxic $(2.5 \mu \mathrm{M})$ and cytotoxic $(5-25 \mu \mathrm{M})$ concentrations $(n=3)$. Values given are the mean \pm s.d. $* P<0.0$ I $* * P<0.00$ I. 
A

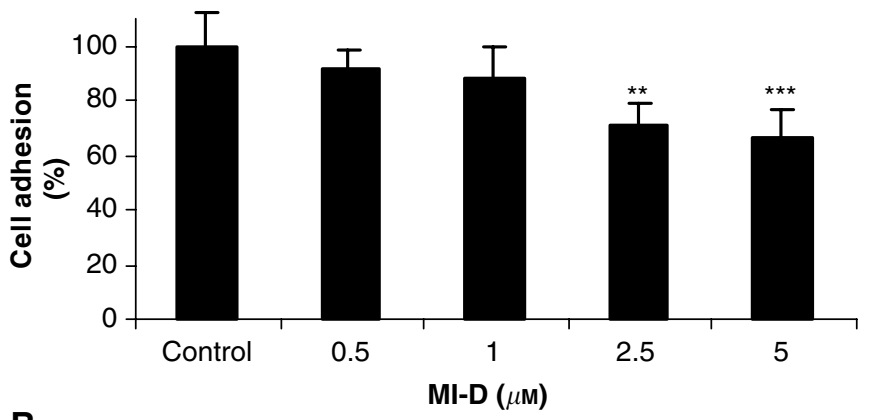

B
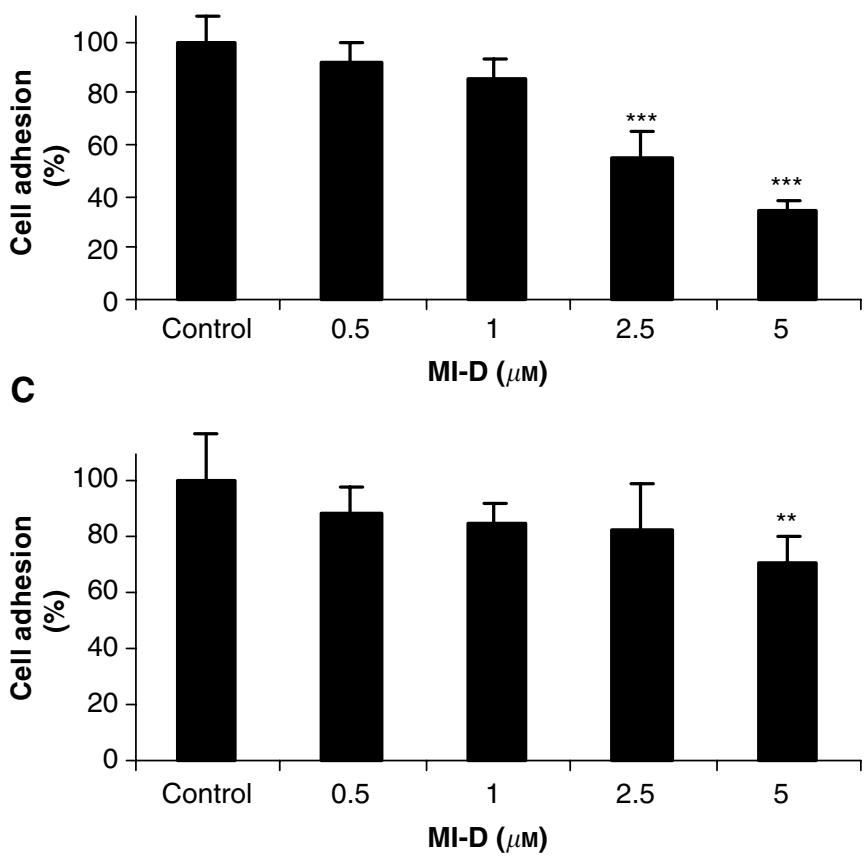

D
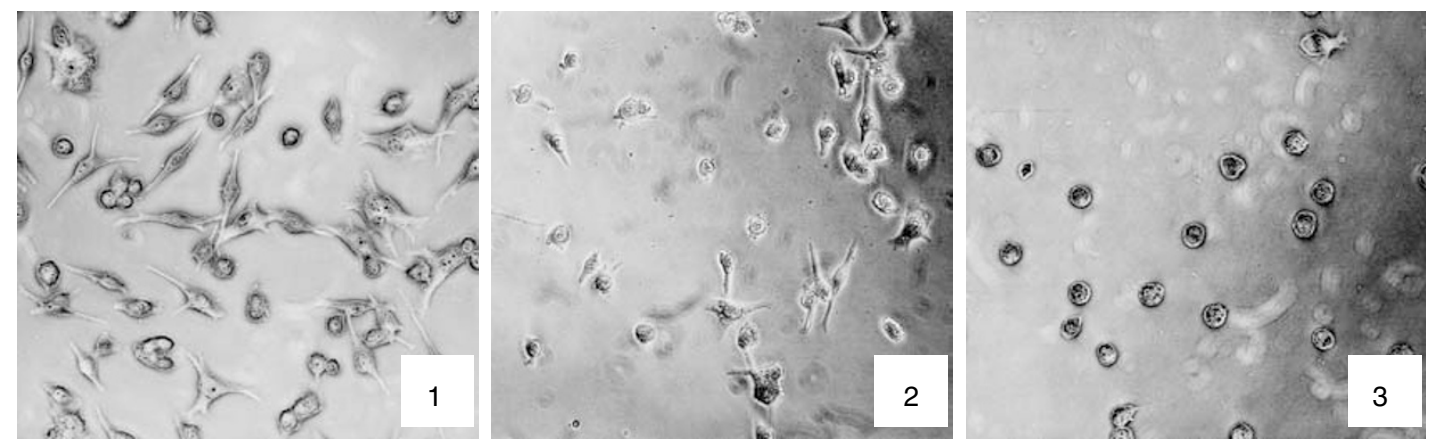

Figure 4 Effects of MI-D on the adhesion of MEL-85 human melanoma cell to ECM constituents. (A) MEL-85 adhesion to laminin. (B) MEL-85 adhesion to fibronectin. (C) MEL-85 adhesion to matrigel. (D) Micrographs of MEL-85 cells adhered to fibronectin. (I) Control cells, (2) cells treated with $2.5 \mu \mathrm{M}$ MI$\mathrm{D}$, (3) cells treated with $5 \mu \mathrm{M}$ MI-D. MEL-85 cells $\left(4 \times 10^{4}\right)$ were added to microculture wells precoated with ECM constituents in the presence of indicated concentrations of MI-D. After a $2 \mathrm{~h}$ incubation, nonadherent cells were washed and adherent cells were fixed and stained with $0.8 \%\left(p v^{-1}\right) \mathrm{crystal}$ violet containing $20 \%$ methanol. After extensive washing, the stained cells were lysed with $50 \%$ ethanol in $0.05 \mathrm{M}$ sodium citrate and the absorbance was measured at $550 \mathrm{~nm}$. $* * P<0.01$ and $* * * P<0.001$.

(Figure $4 \mathrm{~A}$ ) and to fibronectin and matrigel to 34 and $71 \%$, respectively (Figure $4 \mathrm{~B}$ and $\mathrm{C}$ ). The micrographs of the adhesion on fibronectin (Figure 4D) show that MI-D not only reduced the number of cells adhering to fibronectin, but also altered the morphology of MEL-85 cells, which shrinked and became round. These changes were also observed when cells were assayed for their adhesion on laminin and matrigel (data not shown).

\section{Effect of MI-D on MEL-85 morphology}

Figure 5 shows micrographs of MEL- 85 cells stained by Giemsa. It can be observed with treated cells (Figure $5 B$ and $C$ ) that the presence of MI-D gave rise to a disruption of the interactions between cells and substratum. MI-D treated cells are not so spread out as control cells (Figure 5A). The results clearly demonstrate 
significant changes in cell shape, with cells becoming round when compared to those of the control, as was also observed in adhesion assays. The treatment with $25 \mu \mathrm{M}$ MI-D gave rise to shrinkage of some cells, presenting protrusions of the plasma membrane, which were pinched off to form membrane-enclosed similar apoptotic bodies probably with cytoplasmic and nuclear contents. Intense vacuolisation of cytoplasm was observed with treated cells. The concentration of $50 \mu \mathrm{M}$ affected the morphology of almost all of the cells. Condensed chromatin masses with intense eosinophilia and pyknotic nuclei were also observed with treated cells. Morphometric analysis permitted quantification of morphological changes and showed a reduction of $35 \%$ in the area of cells treated with $50 \mu \mathrm{M}$ MI-D. This concentration reduced cell elongation to $56 \%$ and increased cell roundness by $112 \%$.

\section{Effect of MI-D on MEL-85 cytoskeleton organisation}

In order to evaluate if the changes on cell shape were due to alterations on the actin organisation, an experiment using phalloidin-FITC conjugate was performed (Kusano et al, 2000). As can be observed in Figure 6, organisation of actin cytoskeleton was completely disturbed by MI-D treatment. Fluorescence labelling of MEL-85 cells treated with MI-D did not give rise to the overall pattern that was observed in control cells, which showed a considerable organisation of F-actin fibres all over the cell body. MI-D treatment induced a reorganisation of the F-actin cytoskeleton architecture. Cells in the presence of MI-D did not spread and the filamentous structures disassembled or were reorganised to accumulate in the submembraneous area. Actin filaments turned into actin granules mainly localised on the edge of MEL- 85 cells. These results point to a disruption of interactions between cells and the extracellular matrix.

\section{DISCUSSION}

We are now able to show that MI-D has considerable cytotoxic and antiproliferative effects on human melanoma cell lines. These effects seem to be even more aggressive on human melanoma cells than those observed with B16-F10 murine melanoma cells (SenffRibeiro et al, 2003, 2004). For example, a dose of $10 \mu \mathrm{M}$ after $48 \mathrm{~h}$ incubation, on B16-F10 melanoma cells diminished their viability to $\sim 80 \%$ (Senff-Ribeiro et al, 2003, 2004) and in all the four human melanoma cell lines the viability was lower than $30 \%$ under these conditions. Interestingly, MI-D at a low concentration $(5 \mu \mathrm{M})$, gave rise to effects of a different magnitude on the viabilities of

A

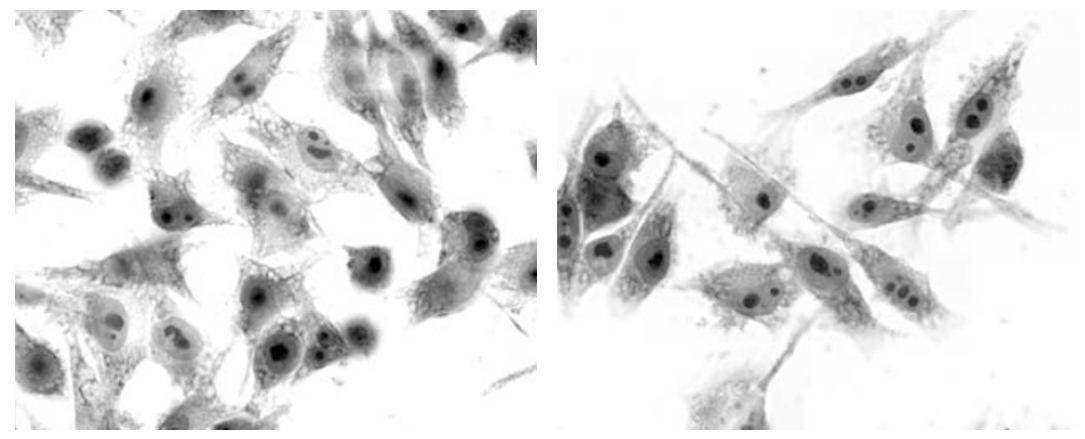

B

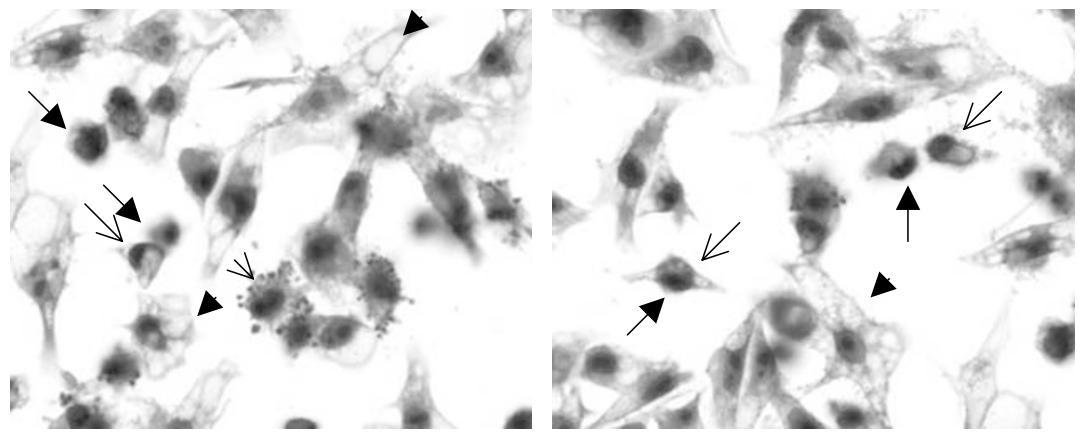

C
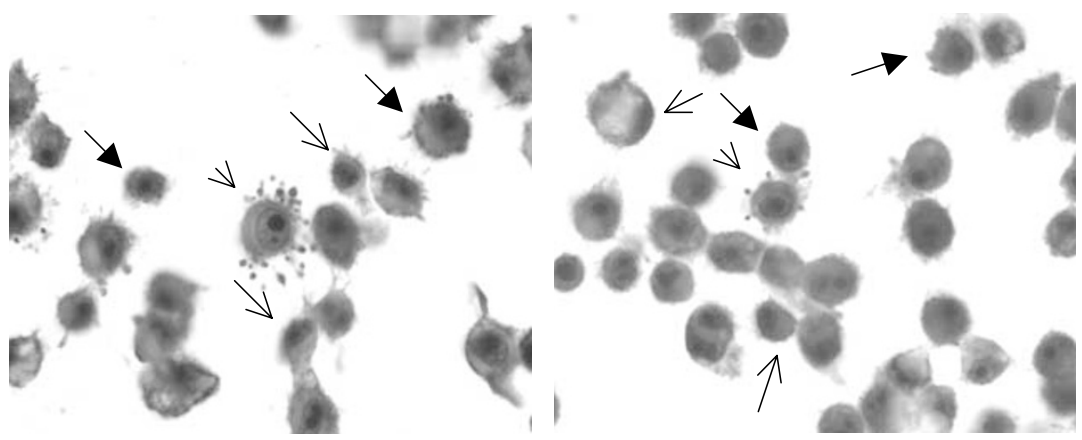

Figure 5 Effects of MI-D on the morphology of MEL-85 cells. (A) Micrographs of control cells. (B) Micrographs of MEL-85 cells treated with $25 \mu \mathrm{M}$ MI-D. (C) Micrographs of MEL-85 cells treated with $50 \mu \mathrm{M}$ MI-D. MEL-85 cells were treated for $2 \mathrm{~h}$, fixed and stained with Giemsa. Samples were observed using a bright-field microscope (Olympus BX40). Closed arrows point to cell shrinkage. Closed arrowheads show vacuolisation of cytoplasm. Open arrows indicate chromatin condensation. Open arrowheads indicate bleb formation in cell membranes $(\times 400)$. 
A
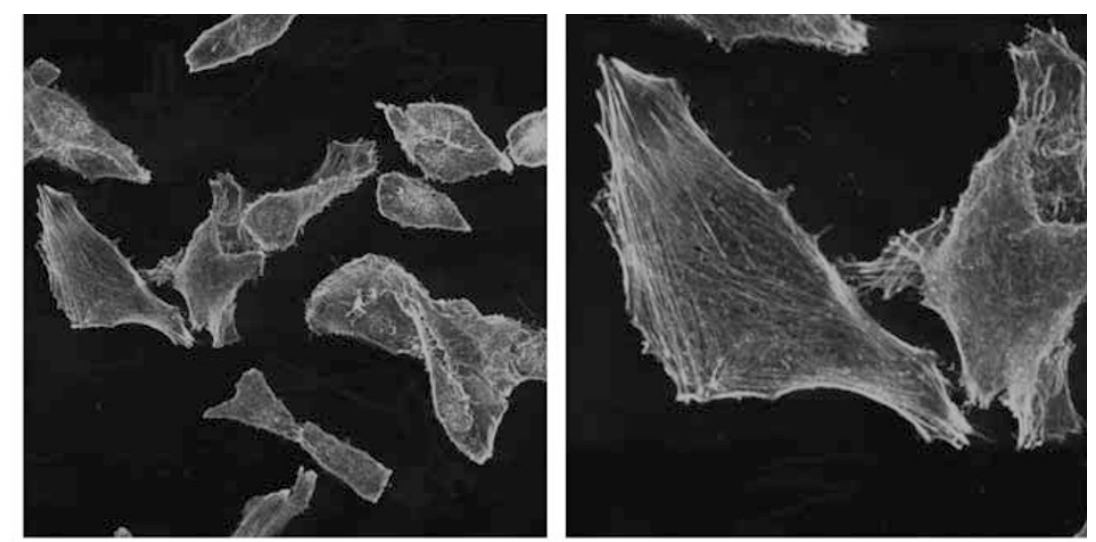

B
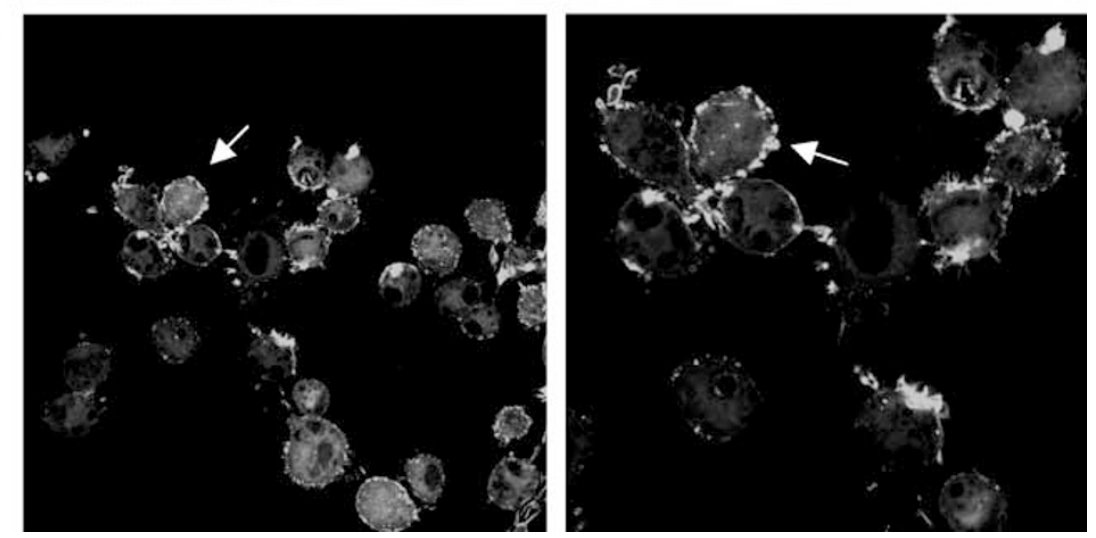

Figure 6 Effects of MI-D on F-actin cytoskeleton organisation of MEL-85 cells. (A) Micrographs of MEL-85 control cells $(\times 600)$. (B) MEL-85 control cells at a higher magnification showing details of well-organised F-actin cytoskeleton $(\times 1450)$. (C) Micrographs of MEL-85 cells treated with $50 \mu \mathrm{M}$ MI-D $(\times 600)$. (D) MEL-85 treated with $50 \mu \mathrm{M}$ MI-D, cells under a higher magnification, depicting disturbances to the organisation of $\mathrm{F}$-actin molecules, concentrated at the edge of cells with a granular pattern (arrow) ( $\times$ I200). MEL-85 cells were treated with MI-D, fixed and labelled with a phalloidin-FITC conjugate and observed at a confocal fluorescence microscope (Confocal Radiance 2100, Bio-Rad) coupled to a Nikon Eclipse 800 with plan apochromatic objectives.

human melanoma cells. Under this condition, MEL-85 and MEWO cell lines (Figure 2A and D) were more sensitive to MI-D than SKMEL and A2058 (Figure 2B and C). Inhibitions of different magnitude on the cell growth of different human melanoma cell lines were also observed. The concentration of $5 \mu \mathrm{M}$ allowed MEL85 growth at a lower rate than that of the control (Figure $3 \mathrm{~A}$ ), but completely inhibited the growth of SK-MEL cells (Figure 3B). The results on viability and proliferation are compatible. As one can observe in Figures 2 and 3, MI-D was very cytotoxic to human melanoma cells and had also an antiproliferative effect. The antiproliferative effect of MI-D was present at both noncytotoxic and cytotoxic doses. The effects of MI-D on the viability and proliferation of the various human melanoma cell lines show MI-D to be a toxic drug for human melanoma cells.

Since tumour cell adhesion to ECM constituents is a fundamental step in tumour development and invasion (Mishima et al, 1998), we investigated the effect of MI-D on MEL-85 melanoma cells adhesion to laminin, fibronectin and matrigel. Low MI-D doses were used in order to minimise its extensive metabolic effects, so that the drug was used at subcytotoxic concentration to evaluate MEL- 85 adhesion to ECM. Overall, $5 \mu \mathrm{M}$ MI-D caused a slight decrease of $\sim 5 \%$ on MEL- 85 viability after $2 \mathrm{~h}$. Under such an experimental condition, MI-D was able to inhibit cell adhesion when it was incubated with the cells for $2 \mathrm{~h}$. Analysing the images of experiments (Figure 4D), we can observe that MI-D treatment promoted loss of cell spreading, which became round, suggesting a possible activity of MI-D on cytoskeleton organisation. These observations were confirmed by morphological and F-actin analyses. Loss of overall cell shape accompanied by cell shrinkage, membrane blebbing and chromatin condensation, besides disturbance of the cytoskeleton organisation, are often observed on apoptotic cells (Hengartner, 2000). The effects of MI-D on MEL-85 adhesion on ECM and morphology may be related to its cytotoxic activity. Although the four different cell lines showed slightly different sensitivities to MI-D, all of them responded to MI-D in a very similar way, so that the MEL-85 results on adhesion, morphology and cytoskeleton organisation probably represent an action of MI-D on human melanoma cell lines.

MI-D is an uncoupler of mitochondrial phosphorylation (Cadena et al, 1998), whose effects on membranes have been recognised (Cadena et al, 2002). Touching on this question, MI-D is an inhibitory uncoupler (Cadena et al, 1998) and according to Skulachev (1998) and others (Colombo et al, 2001), in some instances, an uncoupling action could explain the therapeutic effect of a drug. This seems true for the antitumour action of carbonylcyanide- $m$-chlorophenylhydrazone (CCCP) (Newell and Tannock, 1989) and other anticancer drugs (Keller et al, 1992). The induction of apoptosis could be a consequence of the cytotoxic activity of MI-D, as it is already known that drugs, which affect mitochondrial metabolism, might facilitate the induction of cell death and overcome apoptosis resistance in cancer cells (Susin et al, 1998; Colombo et al, 2001). Moreover, since membrane proteins are highly dependent on membrane organisation and fluidity (Lopez and Kosk-Kosika, 1997), the effects of MI-D on membranes could disturb recognition sites, which are necessary for adhesion.

In conclusion, MI-D is a potent drug against human melanoma cells and this is the first study on its effects against these cells, as well as for a mesoionic compound of the 1,3,4-thiadiazolium class. 
Besides its cytotoxic properties, MI-D also interferes in cell features involved in tumour development, such as adhesion to ECM components. These results, combined with previous data (Senff-Ribeiro et al, 2003, 2004) that showed MI-D to be a potent drug against B16-F10 murine melanoma both in vitro and in vivo, emphasise that MI-D could be a promising drug for the treatment and study of melanoma.

\section{ACKNOWLEDGEMENTS}

We thank Professor Dr RR Brentani, Ludwig Institute for Cancer Research (São Paulo, SP, Brazil), for providing the human melanoma cell lines used in our study.

This study was supported by PRONEX, CAPES, FUNDAÇÃO ARAUCÁRIA and CNPq.

\section{REFERENCES}

Badachikar SV, Tikare RK, Puranik GS (1986) Synthesis, reactions and biological activity of 3-[ $p$-( $N$-methyl/ethyl- $N$-phenylcarbamoyl $)]$ phenylsydnones. Indian J Chem 25B: 1079-1080

Cadena SMSC, Carnieri EGS, Echevarria A, Oliveira MBM (1998) Effect of MI-D, a new mesoionic compound, on energy-linked functions of rat liver mitochondria. FEBS Lett 440: 46-50

Cadena SMSC, Carnieri EGS, Echevarria A, Oliveira MBM (2002) Interference of MI-D, a new mesoionic compound, on artificial and native membranes. Cell Biochem Funct 20: $31-37$

Cheung KK, Echevarria A, Galembeck S, Maciel MAM, Miller J, Rumjanek VM, Simas AM (1992) Mesoionic compounds 3. Structure of the hydrochloride of 5-(4-methoxyphenyl)-1,3,4-thiadiazolium-2-phenylamine. Acta Crystallogr 48: 1471-1474

Colombo P, Gunnarsson K, Iatroupoulos M, Brughera M (2001) Toxicological testing of cytotoxic drugs (Review). Int J Oncol 19: $1021-1028$

Corell T, Pedersen SB, Lissau B, Moilanen E, Mëtsa-Ketelä T, Kankaanranta H, Vuorinen P, Vapaatalo H, Rydell E, Andersson R, Marcinkiewicz E, Korbut R, Gryglewski RJ (1994) Pharmacology of mesoionic oxatriazole derivatives in blood, cardiovascular and respiratory systems. Pol J Pharmacol 46: $553-566$

Engvall E, Ruoslahti E (1977) Binding of soluble form of fibroblast surface protein, fibronectin, to collagen. Int J Cancer 20: 1-5

Grynberg N, Gomes R, Shinzato T, Echevarria A, Miller J (1992) Some new aryl sydnones: effects on murine tumors. Anticancer Res 12: $1025-1028$

Grynberg N, Santos AC, Echevarria A (1997) Synthesis and in vivo antitumor activity of new heterocycles derivatives of 1,3,4-thiadiazolium2-aminide class. Anti-Cancer Drugs 8: 88-91

Hengartner MO (2000) The biochemistry of apoptosis. Nature 407: $770-776$

Hogg N, Darley-Usmar VM, Wilson MT, Moncada S (1992) Production of hydroxyl radicals from simultaneous generation of superoxide and nitric oxide. Biochem J 281: 419-424

Kankaanranta H, Rydell E, Peterson AS, Holm P, Moilanen E, Corell T, Karup G, Vuorinen P, Pedersen SB, Wennmalm A, MetsaKeleta T (1996) Nitric oxide-donating properties of mesoionic 3-aryl substituted oxatriazole-5-imine derivatives. $\mathrm{Br} \mathrm{J}$ Pharmacol 117: $401-406$

Keller BJ, Marsman DS, Popp JA, Thurman RG (1992) Several nongenotoxic carcinogens uncouple mitochondrial oxidative phosphorylation. Biochim Biophys Acta 1102: 237-244

Kier LB, Roche EB (1967) Medicinal chemistry of the mesoionic compounds. J Pharm Sci 56: 148-169

Kleinman HK, McGarvey ML, Hassel JR, Star VL, Cannon FB, Laurie GW, Martin GR (1986) Basement membrane complexes with biological activity. Biochemistry 25(2): $312-318$

Kusano Y, Oguri K, Nagayasu Y, Munesue S, Ishihara M, Saiki I, Yonekura H, Yamamoto H, Okayama M (2000) Participation of syndecan 2 in the induction of stress fiber formation in cooperation with integrin $\alpha 5 \beta 1$ : Structural characteristics of heparan sulfate chains with avidity to $\mathrm{COOH}$-terminal heparin-binding domain of fibronectin. Exp Cell Res 256: $434-444$

Lopez MM, Kosk-Kosika P (1997) Entropy-driven interactions of anesthetics with membrane proteins. Biochemistry 36: 8864-8872

Majid PA, DeFeyter PJF, Van der Wall EE, Wardeh R, Ross JP (1980) Molsidomine in the treatment of patients with angina pectoris. $N$ Engl $J$ Med 302: 1-6
Mishima T, Murata J, Toyoshima M, Fujii H, Nakajima M, Hayashi T, Kato T, Saiki I (1998) Inhibition of tumor invasion and metastasis by calcium spirulan (Ca-SP), a novel sulfated polysaccharide derived from bluegreen alga, Spirulina platensis. Clin Exp Metast 16: 541-550

Montanari CA, Beezer AE, Sandall JPB, Montanari MLC, Miller J, Giesbrecht AM (1992) On the interaction of some mesoionic compounds with Saccharomyces cerevisiae by biological microcalorimetry. Rev Microbiol 23: 274-278

Mosmann T (1983) Rapid colorimetric assay for cellular growth and survival: application to proliferation and cytotoxicity assays. J Immunol Methods 65: 55-63

Moustafa MAA, Eisa HM (1991) Synthesis and antimicrobial activity of 3(substituted - phenyl) - sydnones. Arch Pharmacol 325: 397-401

Newell KJ, Tannock IF (1989) Reduction of intracellular $\mathrm{pH}$ as a possible mechanism for killing cells in acidic regions of solid tumors: effects of carbonylcyanide-3-chlorophenylhydrazone. Cancer Res 49: $4477-4482$

Newton CG, Ramsden CA (1982) Meso-ionic heterocycles. Tetrahedron 38: $2965-3011$

Ollis WD, Ramsden CA (1976) Meso-ionic compounds. Adv Heterocycl Chem 19: $1-121$

Paulsson M, Aumailley M, Deutzmann R, Timpl R, Beck R (1987) Laminin-nidogen complex: extraction with chelating agents and structural characterization. Eur J Biochem 166: 11-19

Phillips HJ (1973) Dye exclusions tests for cell viability. In Tissue Culture, Methods and Applications, Kruse JR, Patterson JRMK (eds) pp 406-408, New York: Academic Press

Rehse K, Ciborski T, Müller B (1995) Platelet aggregation inhibiting and anticoagulant effects of oligoamines. XXVII: inhibition of leucocyte adherence to endothelium by oligoamine RE $1492 \mathrm{C}$ and the NO-donor RE 2047. Arch Pharm (Weinheim) 328: 125 - 126

Rehse K, Konig P (1995) New NO-donors with antithrombotic and vasodilating activities. XII. Mesoionic oxatriazoles and related monocyclic nitrosohydrazine derivatives. Arch Pharmacol 328: 137-142

Rudolph W, Derschinger J (1991) Clinical comparison of nitrates and sydnonimines. Eur Heart $J$ 12: 33-41

Saiki I, Iida J, Murata J, Ogawa R, Nishi N, Sugimura K, Tokura S, Azuma I (1989) Inhibition of the metastasis of murine malignant melanoma by synthetic polymeric peptides containing core sequences of cell-adhesive molecules. Cancer Res 49: 3815-3822

Satyanarayana K, Rao MNA (1995) Synthesis and anti-inflammatory, analgesics and antipyretic testing of 4-[1-oxo-(3-substituted aryl)-2propenyl]-3-phenylsydnones and of 3-[4-[3-(substituted aryl)-1-oxo-2propenyl] phenyl] sydnones. J Pharmacol Sci 84: 263-266

Senff-Ribeiro A, Echevarria A, Silva EF, Veiga SS, Oliveira MBM (2003) Effect of a new 1,3,4-thiadiazolium mesoionic compound (MI-D) on B16F10 murine melanoma. Melanoma Res 13(5): 465-472

Senff-Ribeiro A, Echevarria A, Silva EF, Veiga SS, Oliveira MBM (2004) Antimelanoma activity of 1,3,4-thiadiazolium mesoionics: a structure-activity relationship study. Anti-Cancer Drugs 15(3): $269-275$

Shinzato TO, Grynberg N, Gomes RM, Echevarria A, Miller J (1989) Antitumor activity of new mesoionic compounds against three murine tumors. Med Sci Res 17: 865-866

Skulachev VP (1998) Uncoupling: new approaches to an old problem of bioenergetics. Biochim Biophys Acta 1363: $100-124$

Susin SA, Zamzami N, Kroemer G (1998) Mitochondria as regulators of apoptosis: doubt no more. Biochim Biophys Acta 1366: 151-165 